This document is confidential and is proprietary to the American Chemical Society and its authors. Do not copy or disclose without written permission. If you have received this item in error, notify the sender and delete all copies.

\title{
Exploiting Potential Inversion for Photoinduced Multi- Electron Transfer and Accumulation of Redox Equivalents in a Molecular Heptad
}

\begin{tabular}{|r|l|}
\hline Journal: & Journal of the American Chemical Society \\
\hline Manuscript ID & ja-2018-02443b.R1 \\
\hline Manuscript Type: & Communication \\
\hline Date Submitted by the Author: & 24-Mar-2018 \\
\hline Complete List of Authors: & $\begin{array}{l}\text { Nomrowski, Julia; University of Basel, Department of Chemistry } \\
\text { Wenger, Oliver; University of Basel, Department of Chemistry }\end{array}$ \\
\hline
\end{tabular}

\section{SCHOLARONE ${ }^{m}$ \\ Manuscripts}


Natural oxygenic photosynthesis relies on the temporary accumulation and storage of redox equivalents on plastoquinone and the oxygen-evolving complex before stable reduction and oxidation products are formed. Similar strategies could be interesting for artificial photosynthesis, and therefore significant attention is currently devoted to light-driven accumulation of redox equivalents in artificial systems. ${ }^{1}$ With sacrificial electron donors or acceptors, the accumulation of multiple electrons or holes on a given molecular entity is readily achievable, ${ }^{2}$ but use of such reagents does not permit sustainable solar energy conversion. Consequently, it is desirable to explore the basic concepts that allow for long-lived (>10 ns) accumulation of redox equivalents without sacrificial reagents.

Photoinduced transfer of single electrons has been explored in many covalent donor-acceptor compounds, ${ }^{3}$ but the transfer of multiple electrons is yet a great challenge. ${ }^{4}$ Excitation with two or more photons can trigger a multitude of processes, many of which are either non-productive or even counter-productive. ${ }^{1,5}$ Consequently, only a handful of prior studies achieved light-driven accumulation of redox equivalents in molecular systems without sacrificial reagents. ${ }^{1,5 a, 6,7}$

Scheme 1. Molecular structures of the heptad and three reference compounds.

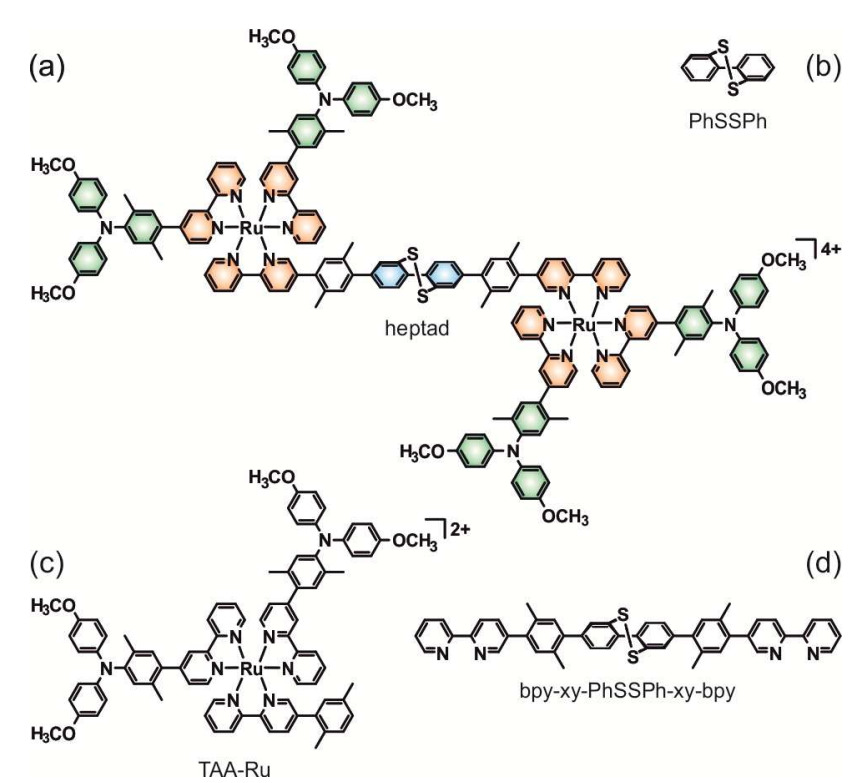

In all these prior studies, the second redox process was thermodynamically more difficult to perform than the first, and this made the accumulation of redox equivalents all the more challenging. We hypothesized that an acceptor exhibiting redox potential inversion, i. e., a compound in which the second reduction occurs more easily than the first, ${ }^{8}$ could facilitate the light-driven accumulation of reduction equivalents. There are a number of possible acceptor units, ${ }^{8-9}$ and we were inspired by prior electrochemical and computational studies of bipyridinium disulfides and dibenzo[1,2]dithiin (PhSSPh) compounds. ${ }^{10}$ We decided to incorporate the latter as a central acceptor unit between two $\mathrm{Ru}(\mathrm{bpy})_{3}{ }^{2+}$ (bpy $=$ 2,2'-bipyridine) photosensitizers equipped with peripheral triarylamine (TAA) donors (Scheme 1a). The plan was to excite both photosensitizers, and to search for a charge-separated state in which the central PhSSPh unit is reduced twice while two peripheral TAA donors are each singly oxidized.

The molecular heptad was synthesized in 18 individual reaction steps as described in the Supporting Information (SI pages S3S14). The spatial separation of PhSSPh acceptor and TAA donors on separate bpy ligands simplified the synthesis but leads to a mixture of diastereomers (SI page S38). However, all elementary electron transfer steps are expected to follow predominantly through-bond pathways, ${ }^{11}$ and thus the analysis of electron transfer kinetics should remain relatively straightforward. 
Cyclic voltammetry of the $\mathrm{PhSSPh}$ reference compound (Scheme 1b) shows the typical features of potential inversion as reported previously for this and closely related compounds (SI page S16). ${ }^{10,12}$ From cathodic scans, a peak potential of $-1.6 \mathrm{~V}$ vs. SCE is measurable, while on return scans the corresponding reoxidation wave is detected at $-0.3 \mathrm{~V}$ vs. SCE. The shift of $1.3 \mathrm{~V}$ between corresponding (two-electron) half-waves is a manifestation of the redox potential inversion. ${ }^{10}$ Single reduction of $\mathrm{PhSSPh}$ generates a disulfide radical anion with considerable tension, which is only released after reduction with a second electron, leading to disulfide bond breaking and consequent rotation of the thiolate groups away from each other to minimize electrostatic repulsion. The peak potential at $-1.6 \mathrm{~V}$ reflects the necessary potential for single reduction, while the potential for the second redox step is commonly associated with the peak potential of the return oxidation $(-0.3 \mathrm{~V})$. Thus, two-electron reduction of $\mathrm{PhSSPh}$ to its dithiolate form $\left(\mathrm{PhS}^{-} \mathrm{PhS}^{-}\right)$is thermodynamically easier by ca. $1.3 \mathrm{~V}$ than one-electron reduction to the dithiin monoanion $\left(\mathrm{PhSSPh}^{-}\right)$. The potentials for TAA oxidation and all $\mathrm{Ru}(\mathrm{bpy}){ }_{3}{ }^{2+}$ related redox processes in the heptad are as expected (SI page S18). ${ }^{13}$

Transient absorption (TA) spectroscopy in conjunction with spectro-electrochemistry (Figure 1) provides direct evidence for the formation of the desired photoproduct comprised of two singly oxidized TAA units and the doubly reduced acceptor in de-aerated $\mathrm{CH}_{3} \mathrm{CN}$ at $22{ }^{\circ} \mathrm{C}$. The $\mathrm{Ru}(\mathrm{bpy})_{3}{ }^{2+}$ units are excited selectively at $532 \mathrm{~nm}$, and this is known to lead to reductive ${ }^{3}$ MLCT excited state quenching by TAA with a time constant of ca. 10-65 ps. ${ }^{7 \mathrm{~g}, \mathrm{~h} \text {, }}$ ${ }^{13}$ Consequently, the characteristic absorption bands of $\mathrm{TAA}^{+}$at 375 and $775 \mathrm{~nm}$ are readily detectable in the transient absorption spectrum recorded in neat $\mathrm{CH}_{3} \mathrm{CN}$ (Figure 1a), in line with the difference spectrum obtained by chemical oxidation of the heptad with $\mathrm{Cu}\left(\mathrm{ClO}_{4}\right)_{2}$ (Figure 1b). The TA spectrum further exhibits a prominent absorption at $520 \mathrm{~nm}$ attributable to the reduced photosensitizer $\left(\mathrm{Ru}(\mathrm{bpy})_{3}{ }^{+}\right)$, as confirmed by comparison to the spectroelectrochemical data obtained from the TAA-Ru reference compound (Scheme 1c, Figure 1c). The most interesting spectral region is around $320 \mathrm{~nm}$ where the electrochemical reduction of the $\mathrm{PhSSPh}$ sub-unit to $\mathrm{PhS}^{-} \mathrm{PhS}^{-}$leads to a diagnostic bleach (Figure 1d) due to a significant change in $\pi$-conjugation associated with this two-electron reduction. A negative signal is indeed observed in the transient absorption spectrum (Figure 1a) at 320 $\mathrm{nm}$ (blue dashed line). When subtracting the contribution of the oxidation product $\mathrm{TAA}^{+}$(green trace in Figure $1 \mathrm{~b}$ ) from the TA spectrum (black trace in Figure 1a), the bleach at $320 \mathrm{~nm}$ is seen more clearly (Figure 1e). This derived spectrum indicates the formation of two different reduction products, namely $\mathrm{PhS}^{-} \mathrm{PhS}$ (bleach at $320 \mathrm{~nm}$ ) and reduced photosensitizer (bands at 375 and $520 \mathrm{~nm}$, bleach at $455 \mathrm{~nm}$ ). We note that the latter exhibits significant absorption at $320 \mathrm{~nm}$ (Figure 1c), weakening the bleach caused by two-electron reduction of $\mathrm{PhSSPh}$ to $\mathrm{PhS}^{-} \mathrm{PhS}^{-}$at that wavelength.

The observation of reduced photosensitizers is due to the formation of $\mathrm{TAA}^{+} / \mathrm{Ru}(\mathrm{bpy})_{3}{ }^{+}$pairs, which can be considered as intermediates on the reaction pathway to the final desired photoproduct comprised of doubly reduced disulfide and two TAA moieties, as discussed below. The key photoproduct comprised of $2 \mathrm{TAA}^{+}$units and doubly reduced disulfide $\left(\mathrm{PhS}^{-} \mathrm{PhS}^{-}\right)$can only be reached as a result of the absorption of two visible photons (SI page S21), hence a quadratic power dependence of the $320-\mathrm{nm}$ bleach would be expected. ${ }^{7 \mathrm{~g}}$ Unfortunately, this signal is too weak for excitation power-dependent measurements (SI page S22), especially in the low-power regime for which such quadratic power dependence could be expected. ${ }^{7 \mathrm{~g}, 14}$

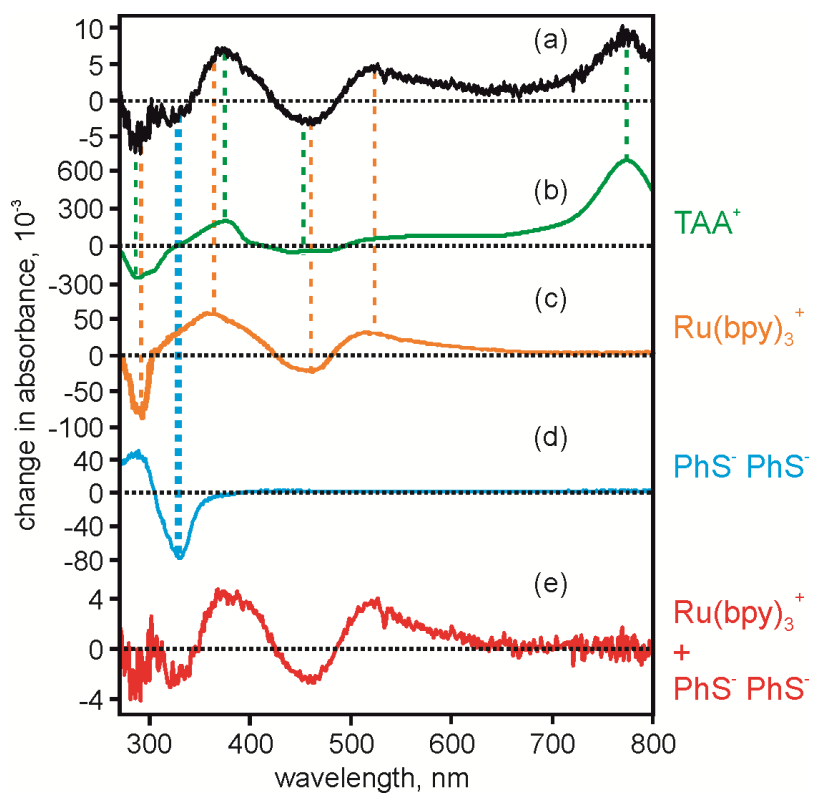

Figure 1. (a) TA spectrum of $5.0 \mu \mathrm{M}$ heptad in $\mathrm{CH}_{3} \mathrm{CN}$, measured in a time window of $100 \mathrm{~ns}$ immediately following excitation at $532 \mathrm{~nm}$. (b) Difference spectrum after oxidation of TAA to $\mathrm{TAA}^{+}$using $\mathrm{Cu}\left(\mathrm{ClO}_{4}\right)_{2}$ and the heptad. (c) Difference spectrum after reduction of TAA- $\mathrm{Ru}$ in $\mathrm{CH}_{3} \mathrm{CN}$ containing 0.1 $\mathrm{M} \mathrm{TBAPF}_{6}$ at $-1.6 \mathrm{~V}$ vs. SCE. (d) Difference spectrum after (twofold) reduction of bpy-xy-PhSSPh-xy-bpy $(99 \mu \mathrm{M})$ in $\mathrm{CH}_{2} \mathrm{Cl}_{2}$ at $-2.0 \mathrm{~V}$ vs. SCE. (e) Spectrum obtained after subtracting the green trace in (b) from the black trace in (a). (Green trace scaled to match the intensity of the black trace at 775 $\mathrm{nm}$ prior to subtraction).

When monitoring the TA signal at $775 \mathrm{~nm}$ after excitation at $532 \mathrm{~nm}$ with laser pulses of ca. $10 \mathrm{~ns}$ duration in $\mathrm{CH}_{3} \mathrm{CN}$, one observes a tri-exponential decay with time components of $\leq 10$, 66 , and $645 \mathrm{~ns}$ in relative importance of $80 \%: 5 \%: 15 \%$, analogous decay behavior is detectable at other wavelengths (SI page S25). Thus, all photoproducts form within the duration of the laser pulses and start to decay immediately. The shortest, instrumentally limited decay component ( $\leq 10 \mathrm{~ns}$ ) is attributed to a proximal $\mathrm{TAA}^{+} / \mathrm{Ru}(\mathrm{bpy})_{3}{ }^{+}$pair. Charge recombination from this state is known to be rapid from closely related molecules. ${ }^{13}$ In time-gated measurements the $320-\mathrm{nm}$ bleach is no longer detectable after a delay of 500 ns (SI page S26), and consequently the time constant of $66 \mathrm{~ns}$ is attributed to the key photoproduct $\left(\mathbf{T A A}^{+}-\mathrm{Ru}(\mathrm{bpy})_{3}{ }^{2+}\right.$. PhS $\left.^{-} \mathbf{P h S}^{-}-\mathrm{Ru}(\mathrm{bpy})_{3}{ }^{2+}-\mathbf{T A A}^{+}\right)$. However, the spectral signatures of $\mathrm{TAA}^{+}$and $\mathrm{Ru}(\mathrm{bpy})_{3}{ }^{+}$remain observable even after $500 \mathrm{~ns}$ hence the lifetime of $645 \mathrm{~ns}$ must be caused by $\mathrm{TAA}^{+} / \mathrm{Ru}(\mathrm{bpy})_{3}{ }^{+}$pairs undergoing slow reverse electron transfer. It seems possible that this occurs in a photoproduct of the type $\mathbf{T} \mathbf{A} \mathbf{A}^{+}-\mathrm{Ru}(\mathrm{bpy})_{3}{ }^{2+}-$ $\mathrm{PhSSPh}-\mathbf{R u}(\mathbf{b p y})_{3}{ }^{+}-\mathrm{TAA}$, in which the oxidizing and reducing equivalents are on distant TAA and photosensitizer units (SI page S25). For an excitation pulse energy of $\sim 34 \mathrm{~mJ}$ using a laser beam irradiating the entire cuvette, we determined an absolute quantum yield of $0.5 \%$ for formation of the desired two-electron reduction product (SI page S27). The formation of $\mathrm{PhS}^{-} \mathrm{PhS}^{-}$via bimolecular disproportionation is not possible on a timescale of $10 \mathrm{~ns}$ at a sample concentration of $5 \mu \mathrm{M} .{ }^{15}$ On a given photosensitizer unit, the presence of both a $\mathrm{TAA}^{+}$and a TAA unit leads to an organic mixed valence situation. ${ }^{16}$

Under acidic conditions, protonation of the dithiolate photoproduct is expected, and consequently we anticipated the formation of an even longer-lived dithiol product. Indeed, in deaerated $\mathrm{CH}_{3} \mathrm{CN}$ with $0.1 \mathrm{M}$ monochloroacetic acid at $22{ }^{\circ} \mathrm{C}$, 
significantly slower transient absorption decays are observed (SI page S29). In the presence of $0.2 \mathrm{M}$ of $p$-toluenesulfonic acid $(\mathrm{TsOH})$ the dithiol photoproduct accumulates under steady-state irradiation with a $455-\mathrm{nm}(3.5 \mathrm{~W})$ LED (Figure 2). The UV-Vis difference spectra recorded as a function of irradiation time (Figure 2a) show both the characteristic changes expected for oxidation of TAA to $\mathrm{TAA}^{+}$(Figure 2b) and those anticipated for the two-fold reduction of the PhSSPh sub-unit (Figure 2c). In this case, the possibility of bimolecular reactions between individual heptads can of course not be excluded. ${ }^{17}$

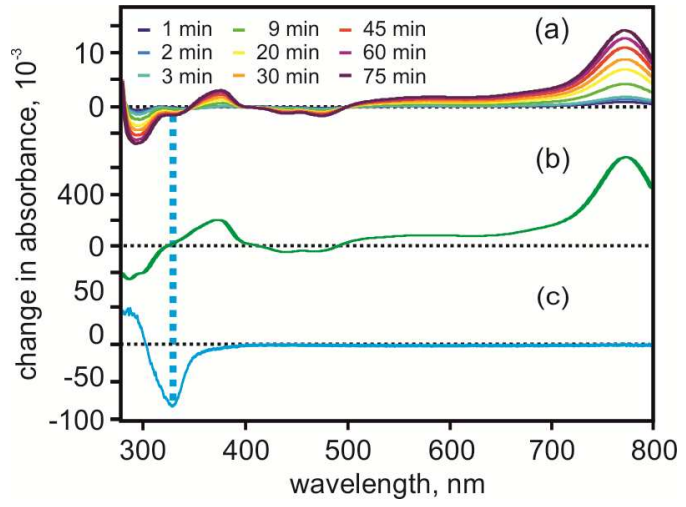

Figure 2. (a) UV-Vis difference spectra after different irradiation times $\left(\lambda_{\text {exc }}=455 \mathrm{~nm}\right)$ from a $5.3 \mu \mathrm{M}$ solution of the heptad in $\mathrm{CH}_{3} \mathrm{CN}$ with $0.2 \mathrm{M}$ TsOH. (b) Difference spectrum obtained by chemical oxidation of the heptad with $\mathrm{Cu}\left(\mathrm{ClO}_{4}\right)_{2}$. (b) Difference spectrum obtained after reduction of bpy-xy$\mathrm{PhSSPh}-\mathrm{xy}$-bpy $(99 \mu \mathrm{M})$ in $\mathrm{CH}_{2} \mathrm{Cl}_{2}$ at $-2.0 \mathrm{~V}$ vs. SCE.

Next, we explored whether the heptad can function as a multielectron donating photocatalyst. With its photogenerated aromatic dithiolate or dithiol entity, the heptad was anticipated to undergo thiolate-disulfide interchange with aliphatic disulfides such as trans-4,5-dihydroxy-1,2-dithiane (DTT ${ }^{\mathrm{ox}}$ ) as illustrated in Scheme $2 .{ }^{18}$ We hypothesized that after formation of the $\mathrm{PhS}^{-} \mathrm{PhS}^{-}$photoproduct seen in Figure 1a/e, the $\mathrm{TAA}^{+}$moieties can be reduced back to neutral TAA with a sacrificial electron donor. Nucleophilic attack of the $\mathrm{PhS}^{-} \mathrm{PhS}^{-}$dithiolate at the $\mathrm{DTT}^{\text {ox }}$ disulfide can then form the aliphatic dithiolate DTT ${ }^{\text {red }}$ in two steps, coupled to oxidation of $\mathrm{PhS}^{-} \mathrm{PhS}^{-}$to the aromatic $\mathrm{PhSSPh}$ disulfide, thereby closing the catalytic cycle. Using $0.1 \mathrm{M}$ triethylamine (TEA) as a sacrificial donor, $22 \mathrm{mM} \mathrm{DTT}^{\mathrm{ox}}$ substrate, and $20 \mu \mathrm{M}$ heptad in dry, de-aerated $\mathrm{CH}_{3} \mathrm{CN}$ at $22{ }^{\circ} \mathrm{C}$, photoirradiation at $455 \mathrm{~nm}$ with an LED $(3.5 \mathrm{~W})$ for 20 hours led to the desired DTT ${ }^{\text {red }}$ product, and a turnover number (TON) of 41 was determined for the heptad catalyst (SI page S32). When using either $40 \mu \mathrm{M} \mathrm{Ru}(\text { bpy })_{3}{ }^{2+}$ or TAA-Ru reference compound, TONs of only 9 were determined. Absolute product yields are low $(3.6 \%$ in the case of the heptad), because the equilibrium of the reaction $\mathrm{PhS}^{-} \mathrm{PhS}^{-}+$ $\mathrm{DTT}^{\mathrm{ox}} \leftrightarrows \mathrm{PhSSPh}+\mathrm{DTT}^{\text {red }}$ strongly disfavors product formation hence this is not a shortcoming of the heptad catalyst (SI page S33). The observation that the heptad catalyzes the reaction ca. 4.5 times better than the reference compounds is consistent with a significant contribution of the thiolate-disulfide interchange mechanism in Scheme 2 and represents an important proof-ofconcept. The reference compounds instead are likely to lead to DTT $^{\text {red }}$ via a single electron transfer route. ${ }^{19}$ The use of TEA favors this pathway, because its primary oxidation and deprotonation leads to a highly reducing $\alpha$-aminoalkyl radical that can provide a second electron in a subsequent dark reaction after an initial light-induced reaction step. ${ }^{20}$ Expectedly, control experiments performed in the dark or in absence of TEA led to no product (SI page S32).
Scheme 2. Proposed mechanism for the catalytic reduction of an aliphatic disulfide (DTT ${ }^{\mathrm{ox}}$ ).

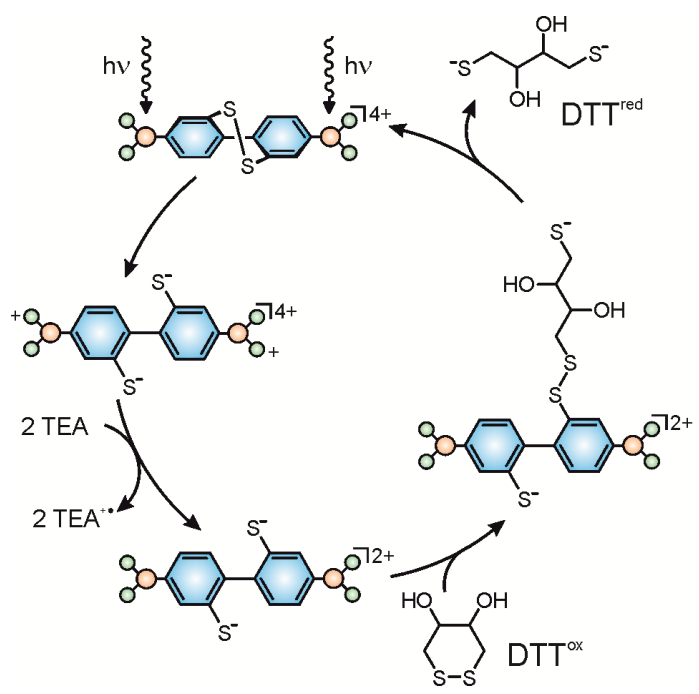

In summary, potential inversion can be exploited for the lightdriven accumulation of redox equivalents without sacrificial reagents. In neat $\mathrm{CH}_{3} \mathrm{CN}$, the aromatic disulfide acceptor is converted to its dithiolate form after excitation of two $\mathrm{Ru}(\mathrm{bpy})_{3}{ }^{2+}$ sensitizers with visible light, and this photoproduct lives for ca. 66 ns before reverse electron transfer with the covalently attached $\mathrm{TAA}^{+}$occurs. The quantum yield for formation of this photoproduct was $0.5 \%$. In the presence of strong acid, proton-coupled electron transfer (PCET) leads to a stable dithiol. When using excess external reductant, the heptad catalyzes thiolate-disulfide interchange with an aliphatic substrate, thereby providing the important proof-of-principle that charge-accumulated states of donor-sensitizer-acceptor compounds are useful for light-driven multi-electron catalysis.

\section{ASSOCIATED CONTENT}

\section{Supporting Information}

Detailed synthetic protocols and characterization data, description of equipment and methods, supplementary electrochemical and spectroscopic data, and detailed thermochemical discussion (PDF).

\section{AUTHOR INFORMATION}

\section{Corresponding Author}

oliver.wenger@unibas.ch

\section{ACKNOWLEDGMENT}

Funding from the Swiss National Science Foundation through grant number 200021-146231/1 is gratefully acknowledged. Dr. Christoph Kerzig, Dr. Xingwei Guo, and Dr. Christopher B. Larsen are acknowledged for valuable discussions and input.

\section{REFERENCES}

(1) Hammarström, L., Acc. Chem. Res. 2015, 48, 840-850.

(2) (a) Konduri, R.; Ye, H. W.; MacDonnell, F. M.; Serroni, S.; Campagna, S.; Rajeshwar, K., Angew. Chem. Int. Ed. 2002, 41, 31853187. (b) Matt, B.; Fize, J.; Moussa, J.; Amouri, H.; Pereira, A.; Artero, V.; Izzet, G.; Proust, A., Energy Environ. Sci. 2013, 6, 1504-1508. (c) Manbeck, G. F.; Brewer, K. J., Coord. Chem. Rev. 2013, 257, 1660-1675. (d) Knör, G.; Vogler, A.; Roffia, S.; Paolucci, F.; Balzani, V., Chem. Commun. 1996, 1643-1644. (e) Polyansky, D.; Cabelli, D.; Muckerman, J. T.; Fujita, E.; Koizumi, T.; Fukushima, T.; Wada, T.; Tanaka, K., Angew. Chem. Int. Ed. 2007, 46, 4169-4172. (f) Yamamoto, M.; Föhlinger, J.; 
Petersson, J.; Hammarström, L.; Imahori, H., Angew. Chem. Int. Ed. 2017, 56, 3329-3333. (g) Zedler, L.; Kupfer, S.; de Moraes, I. R.; Wächtler, M.; Beckert, R.; Schmitt, M.; Popp, J.; Rau, S.; Dietzek, B., Chem.-Eur. J. 2014, 20, 3793-3799.

(3) (a) Klein, J. H.; Schmidt, D.; Steiner, U. E.; Lambert, C., J. Am. Chem. Soc. 2015, 137, 11011-11021. (b) Melomedov, J.; Ochsmann, J. R.; Meister, M.; Laquai, F.; Heinze, K., Eur. J. Inorg. Chem. 2014, 2014, 1984-2001. (c) Sukegawa, J.; Schubert, C.; Zhu, X. Z.; Tsuji, H.; Guldi, D. M.; Nakamura, E., Nat. Chem. 2014, 6, 899-905. (d) Lim, G. N.; Obondi, C. O.; D'Souza, F., Angew. Chem. Int. Ed. 2016, 55, $11517-$ 11521. (e) Hu, K.; Blair, A. D.; Piechota, E. J.; Schauer, P. A.; Sampaio, R. N.; Parlane, F. G. L.; Meyer, G. J.; Berlinguette, C. P., Nat. Chem. 2016, 8, 853-859. (f) Delor, M.; Keane, T.; Scattergood, P. A.; Sazanovich, I. V.; Greetham, G. M.; Towrie, M.; Meijer, A.; Weinstein, J. A., Nat. Chem. 2015, 7, 689-695. (g) Waskasi, M. M.; Kodis, G.; Moore, A. L.; Moore, T. A.; Gust, D.; Matyushov, D. V., J. Am. Chem. Soc. 2016, 138, 9251-9257. (h) Linton, K. E.; Fox, M. A.; Palsson, L. O.; Bryce, M. R., Chem.-Eur. J. 2015, 21, 3997-4007. (i) Stasiw, D. E.; Zhang, J. Y.; Wang, G. B.; Dangi, R.; Stein, B. W.; Shultz, D. A.; Kirk, M. L.; Wojtas, L.; Sommer, R. D., J. Am. Chem. Soc. 2015, 137, 9222-9225. (j) Bao, D. D.; Upadhyayula, S.; Larsen, J. M.; Xia, B.; Georgieva, B.; Nunez, V.; Espinoza, E. M.; Hartman, J. D.; Wurch, M.; Chang, A. D.; Lin, C. K.; Larkin, J.; Vasquez, K.; Beran, G. J. O.; Vullev, V. I., J. Am. Chem. Soc. 2014, 136, 12966-12973. (k) Tyson, D. S.; Luman, C. R.; Castellano, F. N., Inorg. Chem. 2002, 41, 3578-3586. (1) Wiberg, J.; Guo, L. J.; Pettersson, K.; Nilsson, D.; Ljungdahl, T.; Mårtensson, J.; Albinsson, B., J. Am. Chem. Soc. 2007, 129, 155-163.

(4) Kuss-Petermann, M.; Wenger, O. S., Helv. Chim. Acta 2017, 100, e1600283.

(5) (a) Pellegrin, Y.; Odobel, F., Coord. Chem. Rev. 2011, 255, 25782593. (b) Favereau, L.; Makhal, A.; Pellegrin, Y.; Blart, E.; Petersson, J.; Goransson, E.; Hammarström, L.; Odobel, F., J. Am. Chem. Soc. 2016, 138, 3752-3760. (c) Knör, G., Coord. Chem. Rev. 2015, 304, 102-108.

(6) (a) Bonn, A. G.; Wenger, O. S., Chimia 2015, 69, 17-21. (b) Ghaddar, T. H.; Wishart, J. F.; Thompson, D. W.; Whitesell, J. K.; Fox, M. A., J. Am. Chem. Soc. 2002, 124, 8285-8289. (c) Chen, H. Y.; Ardo, S., Nat. Chem. 2018, 10, 17-23. (d) Kitamoto, K.; Ogawa, M.; Ajayakumar, G.; Masaoka, S.; Kraatz, H. B.; Sakai, K., Inorg. Chem. Front. 2016, 3, 671-680.

(7) (a) O'Neil, M. P.; Niemczyk, M. P.; Svec, W. A.; Gosztola, D.; Gaines, G. L.; Wasielewski, M. R., Science 1992, 257, 63-65. (b) Imahori, H.; Hasegawa, M.; Taniguchi, S.; Aoki, M.; Okada, T.; Sakata, Y., Chem. Lett. 1998, 721-722. (c) Karlsson, S.; Boixel, J.; Pellegrin, Y.; Blart, E.; Becker, H. C.; Odobel, F.; Hammarström, L., Faraday Discuss. 2012, 155 , 233-252. (d) Karlsson, S.; Boixel, J.; Pellegrin, Y.; Blart, E.; Becker, H. C.; Odobel, F.; Hammarström, L., J. Am. Chem. Soc. 2010, 132, 17977 17979. (e) Young, R. M.; Jensen, S. C.; Edme, K.; Wu, Y. L.; Krzyaniak, M. D.; Vermeulen, N. A.; Dale, E. J.; Stoddart, J. F.; Weiss, E. A.; Wasielewski, M. R.; Co, D. T., J. Am. Chem. Soc. 2016, 138, 6163-6170. (f) Valdez, C. N.; Schimpf, A. M.; Gamelin, D. R.; Mayer, J. M., J. Am. Chem. Soc. 2016, 138, 1377-1385. (g) Orazietti, M.; Kuss-Petermann, M.; Hamm, P.; Wenger, O. S., Angew. Chem. Int. Ed. 2016, 55, 9407-9410. (h) Kuss-Petermann, M.; Orazietti, M.; Neuburger, M.; Hamm, P.; Wenger, O. S., J. Am. Chem. Soc. 2017, 139, 5225-5232. (i) Mendes Marinho, S.; Ha-Thi, M.-H.; Pham, V.-T.; Quaranta, A.; Pino, T.; Lefumeux, C.; Chamaillé, T.; Leibl, W.; Aukauloo, A., Angew. Chem. Int. Ed. 2017, 56, 15936-15940. (j) Tran, T.-T.; Ha-Thi, M.-H.; Pino, T.; Quaranta, A.; Lefumeux, C.; Leibl, W.; Aukauloo, A., J. Phys. Chem. Lett. 2018, 9, 1086-1091.

(8) Evans, D. H., Chem. Rev. 2008, 108, 2113-2144.

(9) Lachmanová, S.; Dupeyre, G.; Tarábek, J.; Ochsenbein, P.; Perruchot, C.; Ciofini, I.; Hromadová, M.; Pospísil, L.; Lainé, P. P., J. Am. Chem. Soc. 2015, 137, 11349-11364.

(10) (a) Hall, G. B.; Kottani, R.; Felton, G. A. N.; Yamamoto, T.; Evans, D. H.; Glass, R. S.; Lichtenberger, D. L., J. Am. Chem. Soc. 2014, 136, 4012-4018. (b) Benniston, A. C.; Hagon, J.; He, X. Y.; Yang, S. J.; Harrington, R. W., Org. Lett. 2012, 14, 506-509. (c) Benniston, A. C.; Allen, B. D.; Harriman, A.; Llarena, I.; Rostron, J. P.; Stewart, B., New J. Chem. 2009, 33, 417-427.

(11) Gray, H. B.; Winkler, J. R., Proc. Natl. Acad. Sci. U. S. A. 2005, 102, 3534-3539.

(12) Cattaneo, M.; Schiewer, C. E.; Schober, A.; Dechert, S.; Siewert, I.; Meyer, F., Chem. Eur. J. 2018, doi: 10.1002/chem.201705022.

(13) Hankache, J.; Niemi, M.; Lemmetyinen, H.; Wenger, O. S., Inorg. Chem. 2012, 51, 6333-6344.
(14) Haefele, A.; Blumhoff, J.; Khnayzer, R. S.; Castellano, F. N., J. Phys. Chem. Lett. 2012, 3, 299-303.

(15) (a) Rosspeintner, A.; Angulo, G.; Vauthey, E., J. Am. Chem. Soc. 2014, 136, 2026-2032. (b) Kuss-Petermann, M.; Wenger, O. S., Angew. Chem. Int. Ed. 2016, 55, 815-819.

(16) Lambert, C.; Wagener, R.; Klein, J. H.; Grelaud, G.; Moos, M.; Schmiedel, A.; Holzapfel, M.; Bruhn, T., Chem. Commun. 2014, 50 , 11350-11353.

(17) Skaisgirski, M.; Guo, X. W.; Wenger, O. S., Inorg. Chem. 2017, $56,2432-2439$.

(18) (a) Singh, R.; Whitesides, G. M., Sulphur-Containing Functional Groups. John Wiley \& Sons: 1993; p 633-658. (b) Fernandes, P. A.; Ramos, M. J., Chem. Eur. J. 2004, 10, 257-266.

(19) Antonello, S.; Daasbjerg, K.; Jensen, H.; Taddei, F.; Maran, F., J. Am. Chem. Soc. 2003, 125, 14905-14916.

(20) DeLaive, P. J.; Lee, J. T.; Sprintschnik, H. W.; Abruna, H.; Meyer, T. J.; Whitten, D. G., J. Am. Chem. Soc. 1977, 99, 7094-7097. 


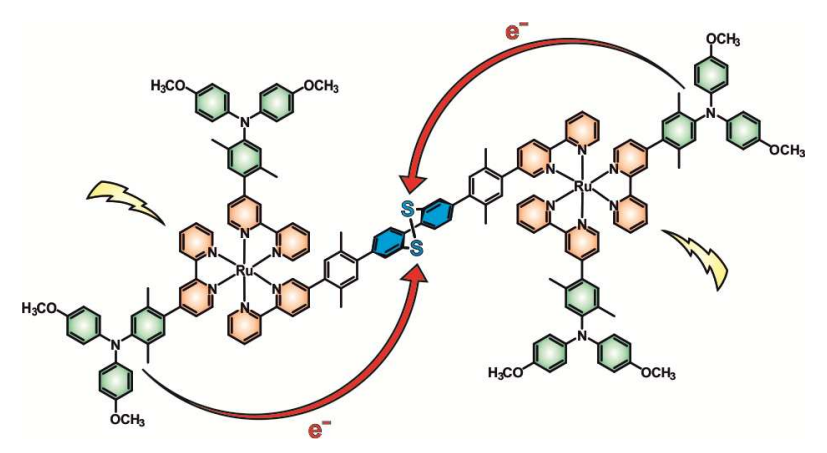

